\title{
Design and flow simulation for a centrifugal pump with double suction impeller
}

\author{
Eugen-Vlad Năstase*
}

Technical University Gheorghe Asachi of Iaşi, Department of Fluid Mechanics, Fluid Machinery and Fluid Power Systems, Iaşi, Romania

\begin{abstract}
Centrifugal pump is a hydraulic machine that is used to transport fluids by the conversion of rotational kinetic energy of impeller into the hydrodynamic energy of the fluid flow. The double-suction centrifugal pump are used for conveyance of a large quantity of water and have wide application due to its stable running, for the balance of axial thrust through by the double suction in impeller, and for a convenient maintenance. Because the design of the centrifugal pump impeller is not a universally standardized one and depends on designer's experience and its technical intuition, in this paper is presented a methodology of design and the fluid flow simulation throughout impeller.
\end{abstract}

\section{Introduction}

Generally a pump is a hydraulic machine which converts mechanical energy into hydraulic energy. The rotational energy typically comes from an electric motor, an engine or a steam turbine. The block diagram which shows the transformation of mechanical energy (torque $\mathrm{M}$ and angular velocity $\omega$ ) into hydraulic energy (head H and flow Q) is shown in Figure1.

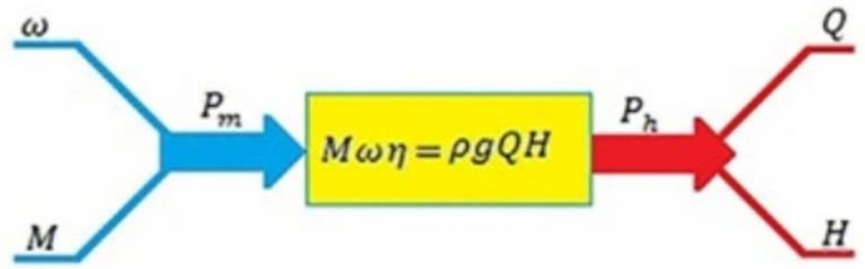

Fig. 1. Block diagram of the energy transformation in a pump.

A centrifugal pump with double suction is presented in the Figure 2. In the volute of the pump fluid enters axially through the eye of the impeller (low pressure area) which rotates at high speed. As the impeller and blades rotate, they transfer momentum to incoming fluid. The fluid accelerates radially outward from the pump chasing and a vacuum is created at the impellers eye that continuously draws more fluid into the pump [1, 2, 3]. As the fluid's velocity increases obviously its kinetic energy increases and the fluid is forced out of the impeller $[1,4,5]$. In the volute the fluid flows through a continuously increasing cross-

${ }^{*}$ Corresponding author: nastase eugenvlad@yahoo.com 
sectional area, where the kinetic energy is converted into fluid pressure (according the Bernoulli's principle). The impeller blades are usually backward-curved.

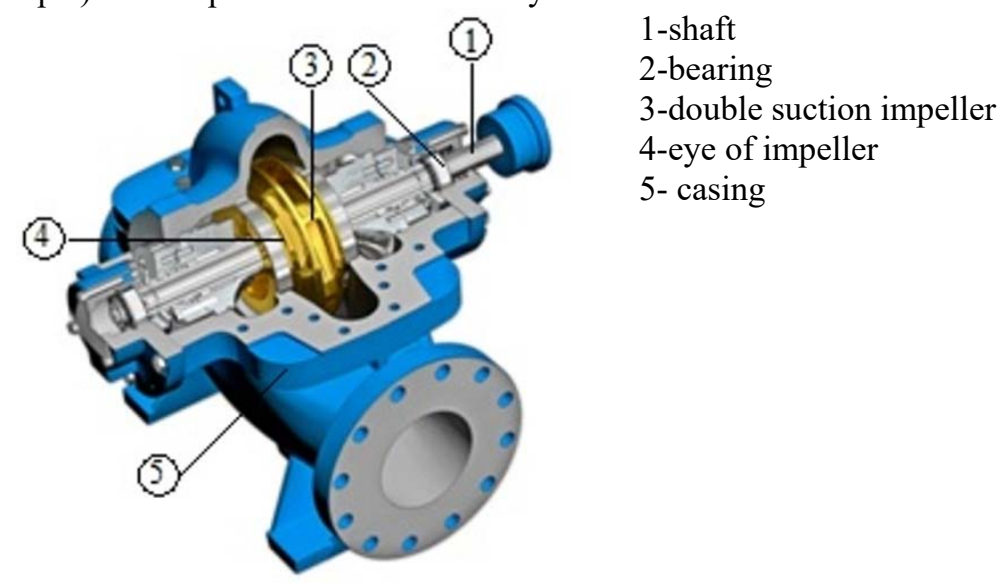

Fig. 2. Overview of main components for a centrifugal pump with double suction impeller.

The impeller is mounted on a shaft. Shaft is a mechanical component for transmitting torque from the drive source to the impeller. This study is structured on 5 sections and presents a methology of design and a computational fluid dynamics simulation for an impeller with double suction. Section 2 will present the design methodology of impeller.

In Section 3, will be shown the characteristics of CFD software and the model preparation for simulation. In section 4 will be analyzed the results of the simulation. Section 5 will present the conclusions of this study.

\section{Design methodology of impeller}

The impeller is the main component determining the pump performance. The impeller that is designed in this paper is for a double suction centrifugal pump that can provide a rate of $0,15 \mathrm{~m}^{3} / \mathrm{s}$ flow in the working conditions whose head is $20 \mathrm{~m}$.
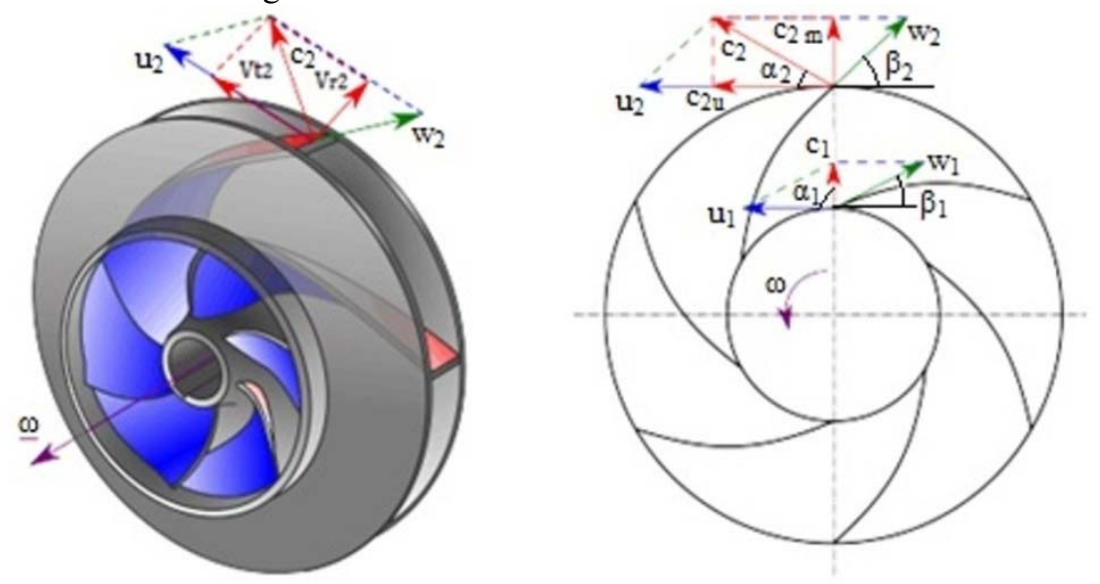

Fig. 3. Components of velocities.

The impeller dimensions are designed based on the head $[6,7,8]$, flow rate and triangle of velocities (Figure 3). The absolute velocity at the inlet and outlet of impeller (c) is composed by tangential velocity (u) and the relative velocity (w) . 
The following are the steps involved in designing a centrifugal impeller.

From the head $(\mathrm{H})$ and flow rate $(\mathrm{Q})$, the kinematic specific speed $\left(\mathrm{n}_{\mathrm{s}}\right)$ is calculated:

$$
n_{s}=3,65 \cdot \frac{n \sqrt{Q}}{H^{\frac{3}{4}}}
$$

From the head $(H)$, flow rate $(\mathrm{Q})$, specific weight of water $\left(\gamma_{\mathrm{w}}\right)$ and overall efficiency $(\eta)$, the shaft power $\left(\mathrm{N}_{\mathrm{sh}}\right)$ required is calculated:

$$
N_{s h}=\frac{H \cdot Q \cdot \gamma_{w}}{\eta}
$$

The shaft diameter $\left(\mathrm{d}_{\mathrm{sh}}\right)$ is found using the formula:

$$
d_{s h}=1,44 \cdot \sqrt[3]{\frac{N_{s h}}{n}}
$$

The hub diameter $\left(\mathrm{d}_{\mathrm{h}}\right)$ is calculated from the empirical relation given below:

$$
d_{h}=(1,1 \div 1,4) \cdot d_{s h}
$$

The velocity $\left(\mathrm{c}_{0}\right)$ at the inlet is estimated using the relationship of below :

$$
c_{0}=0,95 \cdot c_{m 1} \text { where } c_{m 1}=K_{c m 1} \cdot \sqrt{2 \cdot g \cdot H}
$$

With $\mathrm{K}_{\mathrm{cm} 1}$ the coefficient of velocity.

The inlet cross section area $\left(\mathrm{A}_{0}\right)$ is calculeted from the flow rate after accounting for volumetric efficiency $\left(\mathrm{Q}_{\mathrm{v}}\right)$ with the relation:

$$
A_{0}=\frac{Q_{v}}{c_{0}}
$$

The inlet diameter $\left(\mathrm{d}_{1}\right)$ is calculated from the cross section area:

$$
d_{1}=\sqrt{\frac{4 \cdot A_{0}}{\pi}}
$$

Blade inlet angle $\left(\beta_{1}\right)$ is calculated as:

$$
\beta_{1}=\operatorname{arctg} \frac{c_{m 1}}{u_{1}} \text { where } u_{1}=\frac{\pi \cdot d_{1} \cdot n}{60}
$$

Breadth of the impeller $\left(b_{1}\right)$ at the inlet is calculated with the relation:

$$
b_{1}=\frac{A_{1}}{\pi \cdot d_{1}}
$$

The outlet tangential velocity $\left(\mathrm{u}_{2}\right)$ can be calculated with an experimental velocity coefficient $\left(\mathrm{K}_{\mathrm{u} 2}\right)$ as follows:

$$
u_{2}=K_{u 2} \cdot \sqrt{2 \cdot g \cdot H}
$$

The outlet diameter $\left(\mathrm{d}_{2}\right)$ is calculated with the relation:

$$
d_{2}=\frac{60 \cdot u_{2}}{\pi \cdot n}
$$


The breath of the impeller at the outlet is:

$$
b_{2}=\frac{A_{2}}{\pi \cdot d_{2}}
$$

Blade outlet angle $\left(\beta_{2}\right)$ is assumed to lie within the limits of $15^{\circ}$ to $35^{\circ}$.

The number of blades is calculeted by using the following equation:

$$
z=6,5 \cdot \frac{d_{2}+d_{1}}{d_{2}-d_{1}} \cdot \sin \left(\frac{\beta_{1}+\beta_{2}}{2}\right)
$$

The Mathcad software was used to calculate the main impeller dimensions and the numerical values of these are shown in Table 1.

Table 1.The geometric characteristics of impeller.

\begin{tabular}{|c|c|c|c|}
\hline Pump head: $\mathrm{H}(\mathrm{m})$ & 20 & $\begin{array}{c}\text { Oulet tangential velocity: } \mathrm{u}_{2} \\
(\mathrm{~m} / \mathrm{s})\end{array}$ & 19 \\
\hline Flow rate: $\mathrm{Q}\left(\mathrm{m}^{3} / \mathrm{s}\right)$ & 0.15 & Outlet diameter $: \mathrm{d}_{2}(\mathrm{~mm})$ & 380 \\
\hline Shaft power: $\mathrm{N}_{\mathrm{sh}}(\mathrm{KW})$ & 44 & Inlet blade angle: $\beta_{1}\left({ }^{\circ}\right)$ & 17 \\
\hline Shaft diameter: $\mathrm{d}_{\mathrm{sh}}(\mathrm{mm})$ & 60 & Outlet blade angle: $\beta_{2}\left(^{\circ}\right)$ & 30 \\
\hline Specific speed: $\mathrm{n}_{\mathrm{s}}$ & 103.6 & Blade inlet breath: $\mathrm{b}_{1}(\mathrm{~mm})$ & 47 \\
\hline Inlet diameter: $\mathrm{d}_{1}(\mathrm{~mm})$ & 220 & Blade outlet breath: $\mathrm{b}_{2}(\mathrm{~mm})$ & 63.48 \\
\hline $\begin{array}{c}\text { Inlet tangential velocity: } \mathrm{u}_{1} \\
(\mathrm{~m} / \mathrm{s})\end{array}$ & 11.28 & Number of blades & 11 \\
\hline
\end{tabular}

With these dimensions, the 3D model of the rotor is built using the SolidWorks software. The impeller performance is significantly affected by the flow path geometry (vane profile). The vane profile for the impeller presented in figure 4 is developed by arc method.

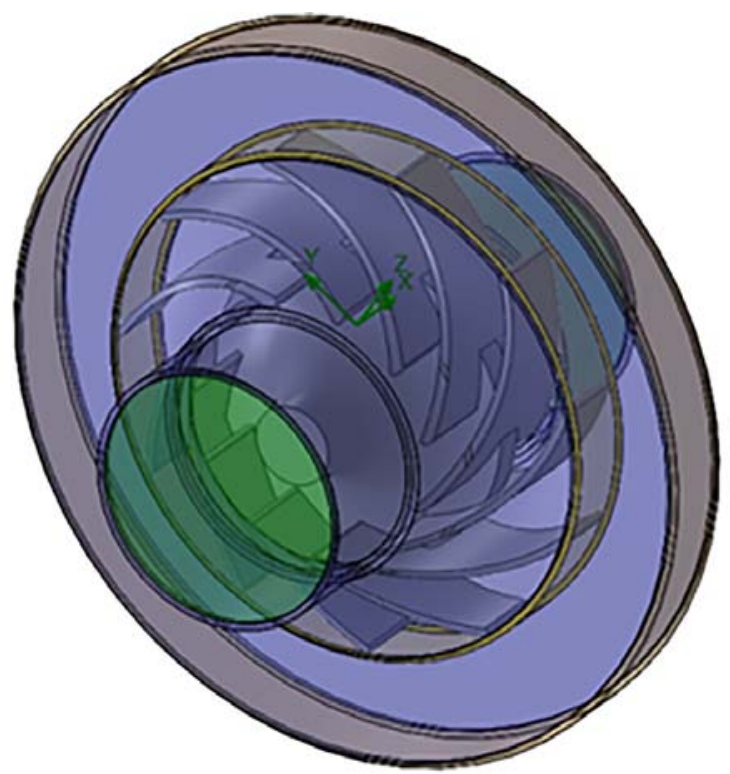

Fig. 4. The impeller for simulation (3D model). 


\section{CFD simulation for double suction impeller}

The pressure and velocity distribution over the blade curvature of impeller was analyzed using a Computational Fluid Dynamics (CFD) package, more exactly the module Solid Works Flow Simulation.

Governing equation for SolidWorks flow simulation solves three-dimensional NavierStokes equation with the finite volume method [8-12]. The first step in CFD simulation is preprocessing. At this step modeling and mesh is generated. Input data for flow analysis is the assigning of computational domain, boundary condition and rotating region. In this phase the boundary conditions are set (Figure 5) and then the simulation is running.

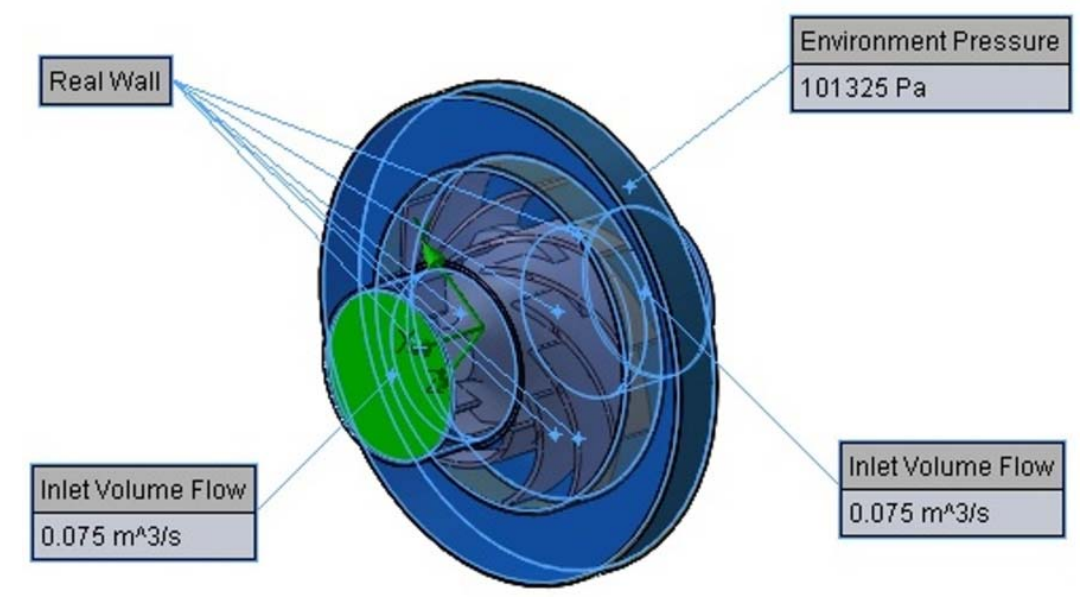

Fig. 5. The diagram of boundary conditions.

\section{Results of simulation}

The results of simulation for velocity and pressure distributions can be see in Figure 6 and Figure 7 respectively.
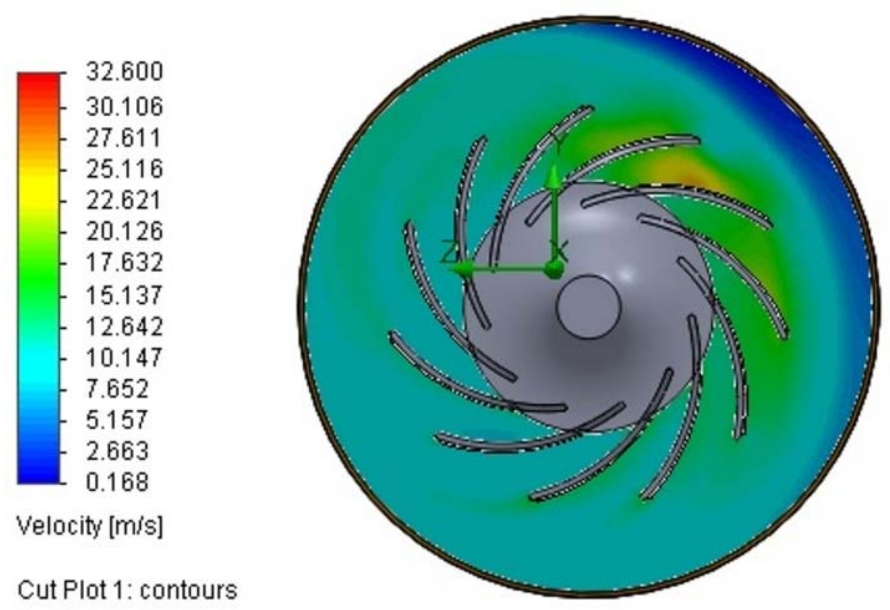

Fig. 6. The diagrams of velocity distribution.

The pressure distribution is increasing from impeller inlet to outlet as it is shown in Figure 7. At the eye pressure is negative. 

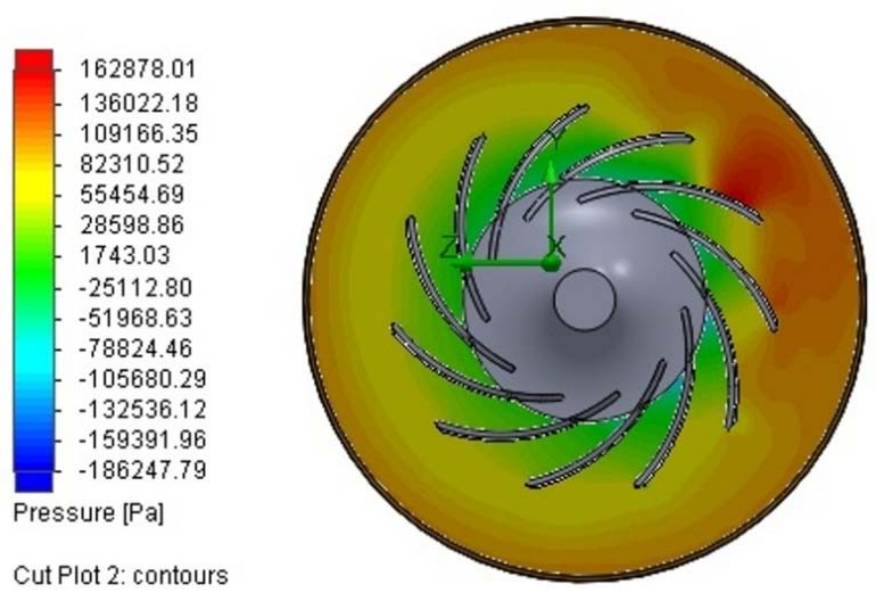

Fig. 7. The flow pressure distribution over the impeller.

\section{Conclusions}

The double suction impeller (3D model) was generated with SolidWorks and analyse in the same software with flow simulation module. The shape of blades for the impeller is created with arc method.

From the speed distribution analysis in the rotor we find that the velocity has decreased in the exit area of the rotor.

The maximum value of the velocity through impeller is $32.6 \mathrm{~m} / \mathrm{s}$, and the velocity distribution can be see in Figure 6.

The velocity distribution is non-uniform because the circulating motion through the impeller.

After the study of pressure distribution, it was observed that is a low pressure at the suction of impeller and the maximum of pressure is after the outlet of impeller.

The results obtained by simulation is comparable with theoretical results which confirms the design methodology.

\section{References}

1. S.N. Shukla, R. Khare, V. Prasad, IJMPERD 7, 5 (2017)

2. D.K. Kalyan, A. Rehman, A.R. Paul, A. Jain, FMFP, 141 (2013)

3. K.U. Kumar, N.V. Reddy, M.R. Reddy, IJMETMR 3,10, (2016)

4. M.S. Ajith, J.M. Issac, IJSETR 10, 7 (2015)

5. B.Sajjan, A.Santhosh, M. Jayaram, K.Anusha, IJESC 6,11 (2016)

6. P. Vyavahare, L.B. Rao, N. Patil, PPME 62,1(2018)

7. Q. Zhang, H. Zhou, Q. Gao, Z. Cui, JOCPR 6, 5 (2014)

8. S.N. Shukla, R. Khare, V. Prasad, IJCIET 7, 6 (2016)

9. S. George, B. George, J. Jayageetha, IJSER 7, 3 (2016)

10. A. Škerlavaj, M. Morgut, D. Jošt, E. Nobile, J.Phys. 796, 1(2017)

11. R.R. Singh, M. Nataraj, VJMS 10, 2 (2014)

12. N.N. Win, IJIRMF 2,11(2016) 